\title{
Event-related potentials evoked by skin puncture reflect activation of $A \beta$ fibers: comparison with intraepidermal and transcutaneous electrical stimulations
}

\author{
Yui Shiroshita ${ }^{1}$, Hikari Kirimoto ${ }^{\text {Corresp., }}{ }^{2}$, Tatsunori Watanabe ${ }^{2}$, Keisuke Yunoki ${ }^{2}$, Ikuko Sobue ${ }^{1}$ \\ ${ }^{1}$ Department of Nursing Science, Graduate School of Biomedical and Health Sciences, Hiroshima University, Hiroshima, Japan \\ 2 Department of Sensorimotor Neuroscience, Graduate School of Biomedical and Health Sciences, Hiroshima University, Hiroshima, Japan \\ Corresponding Author: Hikari Kirimoto \\ Email address: hkirimoto@hiroshima-u.ac.jp
}

Background. Recently, event-related potentials (ERPs) evoked by skin puncture, commonly used for blood sampling, have received attention as a pain assessment tool in neonates. However, their latency appears to be far shorter than the latency of ERPs evoked by intraepidermal electrical stimulation (IES), which selectively activates nociceptive Aठ and C fibers. To clarify this important issue, we examined whether ERPs evoked by skin puncture appropriately reflect central nociceptive processing, as is the case with IES.

Methods. In Experiment 1, we recorded evoked potentials to the click sound produced by a lance device (click-only), lance stimulation with the click sound (click+lance), or lance stimulation with white noise (WN+lance) in eight healthy adults to investigate the effect of the click sound on the ERP evoked by skin puncture. In Experiment 2, we tested 18 heathy adults and recorded evoked potentials to shallow lance stimulation (SL) with a blade that did not reach the dermis ( $0.1 \mathrm{~mm}$ insertion depth); normal lance stimulation (CL) (1 mm depth); transcutaneous electrical stimulation (ES), which mainly activates $A \beta$ fibers; and IES, which selectively activates Aठ fibers when low stimulation current intensities are applied. White noise was continuously presented during the experiments. The stimulations were applied to the hand dorsum. In the SL, the lance device did not touch the skin and the blade was inserted to a depth of $0.1 \mathrm{~mm}$ into the epidermis, where the free nerve endings of Aठ fibers are located, which minimized the tactile sensation caused by the device touching the skin and the activation of $A \beta$ fibers by the blade reaching the dermis. In the $\mathrm{CL}$, as in clinical use, the lance device touched the skin and the blade reached a depth of $1 \mathrm{~mm}$ from the skin surface, i.e., the depth of the dermis at which the $A \beta$ fibers are located.

Results. The ERP N2 latencies for click-only (122 $\pm 2.9 \mathrm{~ms})$ and click+lance (121 $\pm 6.5 \mathrm{~ms})$ were significantly shorter than that for WN+lance (154 $\pm 7.1 \mathrm{~ms})$. The ERP P2 latency for click-only (191 \pm $11.3 \mathrm{~ms}$ ) was significantly shorter than those for click+lance (249 $\pm 18.6 \mathrm{~ms})$ and WN+lance (253 \pm 11.2 $\mathrm{ms})$. This suggests that the click sound shortens the N2 latency of the ERP evoked by skin puncture. The ERP N2 latencies for SL, CL, ES, and IES were $146 \pm 8.3,149 \pm 9.9,148 \pm 13.1$, and $197 \pm 21.2 \mathrm{~ms}$, respectively. The ERP P2 latencies were $250 \pm 18.2$, $251 \pm 14.1,237 \pm 26.3$, and $294 \pm 30.0 \mathrm{~ms}$, respectively. The ERP latency for SL was significantly shorter than that for IES and was similar to that for $E S$. This suggests that the penetration force generated by the blade of the lance device activates the $A \beta$ fibers, consequently shortening the ERP latency.

Conclusions. Lance ERP may reflect the activation of $A \beta$ fibers rather than Aठ fibers. A pain index that correctly and reliably reflects nociceptive processing must be developed to improve pain assessment and 
management in neonates. 


\section{Event-related potentials evoked by skin puncture}

2 reflect activation of $A \beta$ fibers: comparison with

3 intraepidermal and transcutaneous electrical

4 stimulations

5

6 Yui Shiroshita ${ }^{1}$, Hikari Kirimoto ${ }^{2}$, Tatsunori Watanabe ${ }^{2}$, Keisuke Yunoki ${ }^{2}$, Ikuko Sobue ${ }^{1}$

7

$8 \quad{ }^{1}$ Department of Nursing Science, Graduate School of Biomedical and Health Sciences,

9 Hiroshima University, Hiroshima, Japan

$10{ }^{2}$ Department of Sensorimotor Neuroscience, Graduate School of Biomedical and Health

11 Sciences, Hiroshima University, Hiroshima, Japan

12

13 Corresponding Author:

14 Hikari Kirimoto ${ }^{2}$

15 1-2-3, Kasumi, Minami-ku, Hiroshima, 734-8553, Japan

16 Email address: hkirimoto@hiroshima-u.ac.jp 


\section{Abstract}

19 Background. Recently, event-related potentials (ERPs) evoked by skin puncture, commonly

20

21

22

23

24

25

26

27

28

29

30

31

32

33

34

35

36

37

38

39

40

41

42

43

44

45

46

47

48

49

50

51

52

53 used for blood sampling, have received attention as a pain assessment tool in neonates. However, their latency appears to be far shorter than the latency of ERPs evoked by intraepidermal electrical stimulation (IES), which selectively activates nociceptive $\mathrm{A} \delta$ and $\mathrm{C}$ fibers. To clarify this important issue, we examined whether ERPs evoked by skin puncture appropriately reflect central nociceptive processing, as is the case with IES.

Methods. In Experiment 1, we recorded evoked potentials to the click sound produced by a lance device (click-only), lance stimulation with the click sound (click+lance), or lance stimulation with white noise ( $\mathrm{WN}+$ lance) in eight healthy adults to investigate the effect of the click sound on the ERP evoked by skin puncture. In Experiment 2, we tested 18 heathy adults and recorded evoked potentials to shallow lance stimulation (SL) with a blade that did not reach the dermis (0.1 mm insertion depth); normal lance stimulation (CL) (1 mm depth); transcutaneous electrical stimulation (ES), which mainly activates A $\beta$ fibers; and IES, which selectively activates $A \delta$ fibers when low stimulation current intensities are applied. White noise was continuously presented during the experiments. The stimulations were applied to the hand dorsum. In the SL, the lance device did not touch the skin and the blade was inserted to a depth of $0.1 \mathrm{~mm}$ into the epidermis, where the free nerve endings of $A \delta$ fibers are located, which minimized the tactile sensation caused by the device touching the skin and the activation of $A \beta$ fibers by the blade reaching the dermis. In the CL, as in clinical use, the lance device touched the skin and the blade reached a depth of $1 \mathrm{~mm}$ from the skin surface, i.e., the depth of the dermis at which the $A \beta$ fibers are located.

Results. The ERP N2 latencies for click-only $(122 \pm 2.9 \mathrm{~ms})$ and click+lance $(121 \pm 6.5 \mathrm{~ms})$ were significantly shorter than that for WN+lance ( $154 \pm 7.1 \mathrm{~ms})$. The ERP P2 latency for clickonly $(191 \pm 11.3 \mathrm{~ms})$ was significantly shorter than those for click+lance $(249 \pm 18.6 \mathrm{~ms})$ and $\mathrm{WN}+$ lance $(253 \pm 11.2 \mathrm{~ms})$. This suggests that the click sound shortens the N2 latency of the ERP evoked by skin puncture. The ERP N2 latencies for SL, CL, ES, and IES were $146 \pm 8.3$, $149 \pm 9.9,148 \pm 13.1$, and $197 \pm 21.2 \mathrm{~ms}$, respectively. The ERP P2 latencies were $250 \pm 18.2$, $251 \pm 14.1,237 \pm 26.3$, and $294 \pm 30.0 \mathrm{~ms}$, respectively. The ERP latency for SL was significantly shorter than that for IES and was similar to that for ES. This suggests that the penetration force generated by the blade of the lance device activates the $A \beta$ fibers, consequently shortening the ERP latency.

Conclusions. Lance ERP may reflect the activation of $A \beta$ fibers rather than $A \delta$ fibers. A pain index that correctly and reliably reflects nociceptive processing must be developed to improve pain assessment and management in neonates. 


\section{Introduction}

55 Blood sampling is an essential medical procedure, yet the pain sensation associated with skin

56

57

58

59

60

61

62

63

64

65

66

67

68

69

70

71

72

73

74

75

76

77

78

79

80

81

82

83

84

85

86

87

88

89

90

91

92

93 puncture is often a problem. In particular, neonates in neonatal intensive care units frequently experience blood sampling by skin puncture (Cruz, Fernandes \& Oliveira, 2016), and this frequent exposure to unanticipated external nociceptive stimuli has been suggested to adversely affect the neuronal developmental process (Ranger \& Grunau, 2014; Walker, 2019). Repeated painful procedures in neonates reduce the volume of white and gray matter (Brummelte et al., 2012) and lead to behavioral abnormalities (Grunau et al., 2009; Vinall et al., 2014); these adverse effects may last until adolescence (Nosarti et al., 2002, 2008; Anderson \& Doyle, 2003; Grunau, Whitfield \& Fay, 2004; Schmidt et al., 2010; Loe et al., 2011; Lax et al., 2013; Walker et al., 2018). Many researchers have attempted to relieve the pain of skin puncture in the heel in neonates (Pillai Riddell et al., 2015; Stevens et al., 2017) using interventions such as pacifiers, holding, music, and a combination of these (Gao et al., 2018; Peng et al., 2018; Perroteau et al., 2018; Uematsu \& Sobue, 2019; Campbell-Yeo, 2019; Davari et al., 2019). However, some have suggested that the Premature Infant Pain Profile (Stevens et al., 1996; Gibbins et al., 2014) used to evaluate neonatal pain in these studies has issues in terms of pain detection sensitivity (Hartley et al., 2015). Indeed, an index that can be applied to objectively and quantitatively evaluate pain in neonates has yet to be established.

Recently, event-related potentials (ERPs) evoked by nociceptive stimuli have received increasing attention as a pain index in neonates (Slater et al., 2010a; Slater et al., 2010b; Moultrie, Slater \& Hartley, 2017; Shiroshita et al., 2020). However, this index leaves doubts about the research results. In neonates, the ERP evoked by skin puncture in the heel (heel lance) consists of N2P2 and N3P3 waves, and the N3P3 is considered an ERP specific to heel lance (Shiroshita et al., 2021). The N3P3 latency has been reported as $420 \mathrm{~ms}$ (Slater et al., 2010b), $383 \mathrm{~ms}$ (Verriotis et al., 2016), and $403 \mathrm{~ms}$ (Fabrizi et al., 2016) for N3, and as $560 \mathrm{~ms}$ (Slater et al., 2010b), $554 \mathrm{~ms}$ (Verriotis et al., 2016), and $538 \mathrm{~ms}$ (Fabrizi et al., 2016) for P3. However, studies have yet to be conducted that investigate the response to intraepidermal electrical stimulation (IES) or laser stimulation in neonates. Laser stimulation is widely used to generate thermal stimuli and selectively activate heat-sensitive nociceptors (Bromm, Jahnke \& Treede, 1984). IES, as an alternative to laser stimulation, avoids limitations such as skin overheating and lesions due to repeated laser stimulation; moreover, it can selectively activate nociceptive $A \delta$ and C fibers in the epidermal layer of the skin when low stimulation current intensities are applied (Inui et al., 2002; Mouraux, Iannetti \& Plaghki, 2010). However, the exact latency evoked by the activation of $\mathrm{A} \delta$ and $\mathrm{C}$ fibers in neonates remains unknown, and whether the ERP evoked by heel lance in neonates reflects activation of $\mathrm{A} \delta$ or $\mathrm{C}$ fiber is yet to be determined (Shiroshita et al., 2021).

In previous studies of skin puncture in adults in which the same lance device was used as that in a neonatal heel lance, the latency of the ERP in response to lance stimulation at the hand finger [N2: $130 \pm 40 \mathrm{~ms}, \mathrm{P} 2: 258 \pm 61 \mathrm{~ms}$ (Fabrizi et al., 2013); N2: $102 \mathrm{~ms}, \mathrm{P} 2: 249.5 \mathrm{~ms}$ (Fabrizi et al., 2016)] was shorter than that of IES at the hand dorsum [N2: 199-232 ms, P2: 
94

95

96

97

98

99

100

101

102

103

104

105

106

107

108

109

110

111

112

113

114

115

116

117

118

119

120

121

122

123

124

125

126

127

128

129

130

131

132

133

302-377 ms (Inui et al., 2002; Mouraux, Iannetti \& Plaghki, 2010; Otsuru et al., 2010; Kodaira, Inui \& Kakigi, 2014; Mouraux, Marot \& Legrain, 2014; Omori et al., 2017; Kirimoto et al., 2018)] and laser stimulation at the hand dorsum [N2: 185-274 ms, P2: 277-399 ms (Mouraux, Iannetti \& Plaghki, 2010; Otsuru et al., 2010; Lefaucheur et al., 2012)]. The latency of the lance ERP appears to be rather close to the latency of ERPs generated in response to non-nociceptive nerve stimulation, which mainly activates the A $\beta$ fibers at the hand dorsum [N2: 134-147 ms, P2: 235-293 ms (Inui et al., 2002; Mouraux, Iannetti \& Plaghki, 2010; Otsuru et al., 2010)]. It has been reported that thermal, electrical, and mechanical stimuli have different transduction times due to the characteristics of their receptor activation. A $\delta$ fibers activated by laser stimulation are delayed relative to the direct electrical stimulation of IES because skin receptors are excited via temperature conduction (Bromm, Jahnke \& Treede, 1984; Inui et al., 2002). Mechanical stimulation makes it difficult to avoid activation of $A \beta$ fibers with low thresholds and fast conduction velocities (Baumgärtner, Greffrath \& Treede, 2012). Indeed, the blade of the lance stimulation device reaches a depth of $1 \mathrm{~mm}$ from the skin surface (the dermis layer); thus, it penetrates the $0.2 \mathrm{~mm}$ thick epidermal layer where the terminal ends of $\mathrm{A} \delta$ and $\mathrm{C}$ fibers are located (Novotny \& Gommert-Novotny, 1988; Inui et al., 2002). In addition, during the skin puncture procedure, the lance stimulation device is pressed against the puncture site and a button on the device is pressed to push out the blade. We speculate that these features and actions can cause a tactile or vibration sensation, resulting in the activation of the A $\beta$ fibers, which consequently shortens the latency of the lance ERP. A previous finding that latency of ERP evoked by transcutaneous electrical stimulation (ES) activating both $\mathrm{A} \delta$ and $\mathrm{A} \beta$ fibers is shorter than that evoked by a laser stimulation appears to support this speculation (Hird et al., 2018). In addition, lance stimulation produces a click sound when a button on the device is pressed to push out the blade, which potentially affects the lance ERP. Specifically, simple short auditory stimuli have been reported to produce ERP components at around $100 \mathrm{~ms}$ and $180 \mathrm{~ms}$ post-stimuli (Wolpaw \& Penry, 1975; Näätänen \& Picton, 1987; Martin, Tremblay \& Korczak, 2008; Touge et al., 2008; Sakamoto, Nakata \& Kakigi, 2009). Hence, in addition to the activation of the A $\beta$ fibers, we speculate that the click sound produced by the lance device influences the ERP evoked by skin puncture. It is possible that the lance stimulation used commonly in clinical practice does not evoke ERPs reflecting nociceptive processing (i.e., $\mathrm{A} \delta$ and $\mathrm{C}$ fibers).

To reduce the $A \beta$ fiber activation, we created a condition in which tactile pressure and vibration were excluded as much as possible by making a base on which to fix the lance stimulation device and by having a shallower blade insertion depth than the depth used in clinical practice. Although our interest is in neonates, it is impossible to evaluate their sensory thresholds and determine an appropriate ES intensity since they cannot express their feelings verbally. Therefore, healthy adults were used to investigate whether the lance ERP would be appropriate as a parameter for the objective evaluation of nociceptive processing. We conducted two experiments. In Experiment 1, we investigated the effect of the click sound on the ERP evoked by skin puncture. In Experiment 2, we investigated whether A $\beta$ fiber activation is associated with the lance ERP. 


\section{Materials \& Methods}

\section{Subjects}

Eighteen healthy volunteers (13 males and 5 females; 19-34 years old) participated in this study (8 volunteers in Experiment 1 and 18 in Experiment 2). Their height was 153.0-180.0 cm (169.3 $\pm 7.1 \mathrm{~cm})$. They were not undergoing any medical treatments and did not take analgesic drugs within the $48 \mathrm{~h}$ prior to the experiment. The study was approved by the Ethics Committee of Hiroshima University (approval number: E-2044) and written consent was obtained from all subjects.

143

\section{Experimental procedure}

\section{Experiment 1}

Each subject comfortably sat in a recliner with a head pillow and leg rests and placed his/her right arm on the armrest in a neutral position. We recorded evoked potentials (EPs) in response to the click sound produced by a lance device (click-only), shallow lancing (SL) with the click

150

151

152

153

154

155

156

157

158

159

160

161

162

163

164

165

166

167

168

169

170

171

172

173 sound (click+SL), and SL with white noise (WN+SL). Each of these was performed in a random order during one day. SL was applied to the dorsum of the right hand between the first and second metacarpal bones, and the stimulations were performed within $2 \times 2 \mathrm{~cm}$. For click-only, the click sound was produced near the dorsum of the right hand. To avoid habituation, the three stimulation types were performed at intervals of a few minutes.

\section{Three types of stimulation}

\section{Click-only}

We used a lancet (BD Microtainer Quikheel ${ }^{\mathrm{TM}}$ Lancet 368102, Japan Becton, Dickinson, Japan) that is clinically used for the heel lance of neonates. The lance device produces a click sound when a button on the device is pressed. The click sound was produced four times near the dorsum of the right hand without skin puncture.

\section{Click $+S L$}

The lancet housed a $2.5 \mathrm{~mm}$ spring-loaded blade, which is released by pressing a button on the top of the device. After creating the incision, the blade automatically and immediately retracts back inside the device. The original penetration depth was $1 \mathrm{~mm}$. To minimize the tactile sensation caused by the device touching the skin and the activation of $A \beta$ fibers by the blade reaching the dermis (Munger \& Halata, 1983; Mouraux, Iannetti \& Plaghki, 2010), we placed a $0.8 \mathrm{~mm}$ plate between the device and the skin; we also fixed the device to the plate using a fixing stand (NISSIN SEIKI CO., LTD., Japan), which created a space of approximately $0.1 \mathrm{~mm}$ between the plate and the skin surface (Figure 1). Thus, the blade was inserted to a depth of 0.1 $\mathrm{mm}$ into the epidermis, where the free nerve endings of A $\delta$ fibers are located (Novotny \& Gommert-Novotny, 1988; Inui et al., 2002). We performed the click+SL procedure four times. The stimulus location was changed for each stimulation to avoid habituation. 
174

175

176

177

178

179

180

181

182

183

184

185

186

187

188

189

190

191

192

193

194

195

196

197

198

199

200

201

202

203

204

205

206

207

208

209

210

211

212

213

$W N+S L$

The white noise was presented over headphones. We confirmed that the subjects did not hear the click sound from the lance device. We performed the stimulation at least four times and added the number of times when the peak-to-peak amplitude of the EP was below $20 \mu \mathrm{V}$ (4-5 times). The stimulus location was changed for each stimulation to avoid habituation.

\section{Experiment 2}

Each subject comfortably sat in a recliner with a head pillow and leg rests and placed his/her right arm on the armrest in a neutral position. The subjects received four types of stimulation, i.e., SL, clinical lance stimulation (CL), ES, and IES, randomly in one day. White noise was presented over headphones for all the stimulation conditions because we found an effect of the click sound on the ERP evoked by skin puncture (as described below). We confirmed that the subjects did not hear the click sound during the stimulation. The stimulation was applied to the dorsum of the right hand between the first and second metacarpal bones, and all stimulations were performed within $2 \times 2 \mathrm{~cm}$. To avoid habituation, the four stimulation types were provided with intervals of a few minutes between each stimulus. We recorded EPs elicited by the stimulation. To equalize attention across different stimulations, the subject was asked to report using a visual analog scale (VAS), with zero meaning "no pain" and 100 meaning "worst pain", for each stimulation.

\section{Four types of stimulation}

$S L$

The stimulation method was same as $\mathrm{WN}+\mathrm{SL}$ in Experiment 1. We performed SL at least four times and added the number of times when peak-to-peak amplitude of the EP was below $20 \mu \mathrm{V}$ (4-5 times).

\section{$C L$}

In CL, as in clinical use, the surface of the lancet touched the skin and the blade reached a depth of $1 \mathrm{~mm}$ from the skin surface, i.e., the depth of the dermis where $A \beta$ fibers are located. At least four times were performed (4-6 times) and the stimulus location was within $1 \mathrm{~cm}$ from the SL location.

\section{ES}

For tactile stimulation, we applied ES using a bipolar felt-tip electrode (Digitimer DS7; Digitimer, UK). The stimulus was a 1-ms train of triple square wave pulses delivered with an interstimulus interval (ISI) of $2 \mathrm{~ms}$. The stimulus intensity was 1.2-1.5 times the sensory threshold $(0.8 \pm 0.3 \mathrm{~mA})$. The sensory threshold was determined as follows: we started with an intensity of $0.01 \mathrm{~mA}$ and increased it by $0.01 \mathrm{~mA}$ until the subject felt a tactile sensation; the intensity was then reduced by $0.01 \mathrm{~mA}$ until the subject's tactile sensation disappeared; we 
214 determined the stimulus intensity at which clear middle-to-late EPs were obtained without a

215 pricking sensation (Inui et al., 2002) to be 1.2-1.5 times the sensory threshold. We performed 15

216 ESs with an interval of 7-9 s. None of the subjects reported pinprick pain in response to the ES.

217

218 IES

219 For nociceptive stimulation, we used IES, which selectively activates A $\delta$ fibers when low

220 stimulation current intensities are applied (Inui et al., 2002; Mouraux, Iannetti \& Plaghki, 2010).

221

222 The stimulus was delivered using a stimulator (PNS-7000; Nihon Kohden) and a stainless steel

223 concentric bipolar needle electrode (NM-980W; Nihon Kohden). The stimulus was a train of

224 triple triangular wave pulses (a rise and fall time of $0.5 \mathrm{~ms}$ ) with an ISI of $5 \mathrm{~ms}$. The stimulus intensity was $1.5-2.25$ times the sensory threshold $(0.07 \pm 0.02 \mathrm{~mA})$. The sensory threshold was

225

226

227 determined as follows: we started with an intensity of $0.01 \mathrm{~mA}$ and increased it by $0.01 \mathrm{~mA}$ until the subject felt a pricking sensation; the intensity was then reduced by $0.01 \mathrm{~mA}$ until the

228 subject's pricking sensation disappeared; we determined the stimulus intensity at which subjects

229 felt pricking sensations and obtained clear middle-to-late EPs (Inui et al., 2002) at 1.5-2.25 times the sensory threshold. We performed 15 IESs with an interval of 10-15 s.

230

231

\section{Sample size calculation}

232 The sample size was calculated using the following formula:

233

234

$$
\mathrm{n}=\frac{\lambda^{2} C^{2}}{e^{2}}=17.59 \#(1)
$$

235

236

237

where $\lambda$ is 1.96 (95\% confidence interval), $C$ is the coefficient of variance $(0.107)$ obtained from our previous study (Kirimoto et al., 2018), and $e$ is the acceptable error rate of 0.05 . Based on

238

239

240 this calculation, the sample size was set as 18 in the present study.

241

\section{Recording EPs}

EPs were recorded using an amplifier (FA-DL-160, 4 Assist, Japan) with Cz (International 10-20

242 system) as the active electrode because the maximum response has previously been recorded

243 from the $\mathrm{Cz}$ derivation in both electrical and lance stimulations (Kakigi, Shibasaki \& Ikeda,

244 1989; Slater et al., 2010b; Otsuru et al., 2010). The earlobe (A2) was used as a reference. For the

245 ground electrode, a disposable gel electrode was placed on the right forearm (GE Health Care

246 Japan, Tokyo, Japan). The recording was made at a sampling rate of 4,000 Hz with a bandpass

247 filter of 0.1-50.0 Hz. In Experiment 1, average waveforms were created from at least four

248 artifact-free EPs (4-5 times) for the click-only, click+SL, and WN+SL conditions. In Experiment

249 2, average waveforms were created from 12 artifact-free EPs for ES and IES, and from at least

250 four artifact-free EPs (4-6 times) for SL and CL. The EPs for the click-only, click+SL, WN+SL, 251 SL, and CL were time-locked to the time at which an accelerometer (FA-DL-111; 4 Assist, 252 Japan) attached to the experimenter's finger detected the start of lancet button pressing 
253

254

255

256

257

258

259

260

261

262

263

264

265

266

267

268

269

270

271

272

273

274

275

276

277

278

279

280

281

282

283

284

285

286

287

288

289

290

291

(movement of finger); when the button was pressed, the blade was released from the device to incise the skin. The time lag from when the lancet button started to be pressed until the blade reached the skin was about $2 \mathrm{~ms}$ or less as measured by a high-speed camera $(1,200 \mathrm{frames} / \mathrm{s})$, which was considered negligible here.

\section{Data and statistical analysis}

ES and IES evoked negative-positive waveforms (N2-P2) with different latencies. The peak latencies of N2 and P2 for the ES were measured between 120-180 ms and 180-280 ms, respectively, and these values for the IES were measure between 170-250 ms and 250-350 ms, respectively (Inui et al., 2002; Mouraux, Iannetti \& Plaghki, 2010; Otsuru et al., 2010; Kodaira, Inui \& Kakigi, 2014; Mouraux, Marot \& Legrain, 2014; Omori et al., 2017; Kirimoto et al., 2018). Click-only, click+SL, WN+SL, SL, and CL also evoked N2-P2. For the click-only, click+SL, WN+SL, SL, and CL conditions, we created the grand average of individual ERPs across all subjects and then selected the N2 and P2 peaks in the individual ERP waveforms that were located closest to those in the grand average (Fabrizi et al., 2013).

In Experiment 1, we compared the N2 and P2 latencies and N2-P2 amplitudes among the three stimulation conditions (i.e., click-only, click $+\mathrm{SL}$, and $\mathrm{WN}+\mathrm{SL}$ ) using a one-way repeatedmeasures ANOVA. In Experiment 2, we compared the N2 and P2 latencies and N2-P2 amplitudes among the four stimulation conditions (i.e., SL, CL, ES, and IES) using a one-way repeated-measures ANOVA. A Bonferroni correction was used for the post hoc analysis. The VAS score was compared among the four stimulation conditions (i.e., SL, CL, ES, and IES) initially with a Friedman test and then with a Wilcoxon signed-rank test for post hoc analysis. The correlations between the VAS score and N2 or P2 latencies and between the VAS score and N2-P2 amplitudes were calculated using Spearman's rank correlation coefficients. SAS9.4 was used to perform all statistical analyses.

\section{Results}

\section{Experiment 1}

Figure 2 shows the grand averaged waveforms of potentials evoked by click-only, click + SL, and $\mathrm{WN}+\mathrm{SL}$ (N2-P2). The mean and SD of the peak latencies for N2 and P2 are shown in Table 1.

The mean and individual latencies of $\mathrm{N} 2$ and $\mathrm{P} 2$ for each stimulation condition (click-only, click $+\mathrm{SL}$, and $\mathrm{WN}+\mathrm{SL}$ ) are summarized in Figure 3. A one-way repeated-measures ANOVA showed that the latencies of both $\mathrm{N} 2$ and $\mathrm{P} 2$ were significantly different among the three stimulation conditions $\left(\mathrm{N} 2: \mathrm{F}_{(2,14)}=120.3, \mathrm{P}<0.0001, \eta_{\mathrm{p}}^{2}=0.9450 ; \mathrm{P} 2: \mathrm{F}_{(2,14)}=50.89, \mathrm{P}<\right.$ $\left.0.0001, \eta_{\mathrm{p}}^{2}=0.8791\right)$. Post hoc analyses showed that $\mathrm{N} 2$ latencies for the click-only $(122 \pm 2.9$ $\mathrm{ms})$ and click $+\mathrm{SL}(121 \pm 6.5 \mathrm{~ms})$ were significantly shorter than that for the WN+SL $(154 \pm 7.1$ ms: $\mathrm{P}<0.0001$ for click-only; $\mathrm{P}<0.0001$ for click $+\mathrm{SL}$ ). There was no significant difference in N2 latency between the click-only and the click+SL. The P2 latency for the click-only (191 \pm $11.3 \mathrm{~ms})$ was significantly shorter than that for the click+SL $(249 \pm 18.6 \mathrm{~ms}: \mathrm{P}<0.0001)$ and 
292 that for the $\mathrm{WN}+\mathrm{SL}(253 \pm 11.2 \mathrm{~ms}: \mathrm{P}<0.0001)$. There was no significant difference in $\mathrm{P} 2$ 293 latency between the click $+\mathrm{SL}$ and the $\mathrm{WN}+\mathrm{SL}$.

294 A one-way repeated-measures ANOVA showed that the P2 amplitude was also significantly 295 different among the three stimulation conditions $\left(\mathrm{F}_{(2,14)}=6.32, \mathrm{P}=0.0111, \eta_{\mathrm{p}}^{2}=0.4744\right)$, but 296 there was no significant difference in N2 amplitude among the three stimulation conditions 297 (Table 1). Post hoc analyses showed that the P2 amplitude for the click-only condition (14.8 \pm $2985.0 \mu \mathrm{V})$ was significantly shorter than those for the click+SL $(21.4 \pm 4.9 \mu \mathrm{V}: \mathrm{P}=0.0422)$ and $299 \mathrm{WN}+\mathrm{SL}(24.7 \pm 4.5 \mu \mathrm{V}: \mathrm{P}=0.0257)$. There was no significant difference in $\mathrm{P} 2$ amplitude 300 between the click+SL and the $\mathrm{WN}+\mathrm{SL}$.

301

\section{Experiment 2}

304 Figure 4 shows the grand averaged waveforms of potentials evoked by SL, CL, ES, and IES 305 (N2-P2). The mean and SD of the peak latencies for N2 and P2 are shown in Table 2.

The mean and individual latencies of N2 and P2 for each stimulation condition (SL, CL, ES, and IES) are summarized in Figure 5. A one-way repeated-measures ANOVA showed that the latencies of both $\mathrm{N} 2$ and $\mathrm{P} 2$ were significantly different among the four stimulation conditions $\left(\mathrm{N} 2: \mathrm{F}_{(3,51)}=65.51, \mathrm{P}<0.0001, \eta_{\mathrm{p}}^{2}=0.7940 ; \mathrm{P} 2: \mathrm{F}_{(3,51)}=40.54, \mathrm{P}<0.0001, \eta_{\mathrm{p}}^{2}=0.7045\right)$. Post hoc analyses showed that N2 latencies for the SL $(146 \pm 8.3 \mathrm{~ms})$, CL $(149 \pm 9.9 \mathrm{~ms})$, and ES $(148 \pm 13.1 \mathrm{~ms})$ were significantly shorter than that for the IES $(197 \pm 21.2 \mathrm{~ms}: \mathrm{P}<0.0001$ for SL; P $<0.0001$ for CL; P $<0.0001$ for ES). The P2 latencies for the SL ( $250 \pm 18.2 \mathrm{~ms})$, CL ( 251 $\pm 14.1 \mathrm{~ms})$, and ES $(237 \pm 26.3 \mathrm{~ms})$ were significantly shorter than that for the IES $(294 \pm 30.0$ ms: $\mathrm{P}<0.0001$ for SL; $\mathrm{P}<0.0001$ for $\mathrm{CL} ; \mathrm{P}<0.0001$ for ES). There was no significant difference in the N2 and $\mathrm{P} 2$ latencies between SL, CL, and ES.

A one-way repeated-measures ANOVA showed that the N2-P2 amplitudes were also significantly different among the four stimulation conditions $\left(\mathrm{F}_{(3,51)}=11.70, \mathrm{P}<0.0001, \eta_{\mathrm{p}}^{2}=\right.$ $0.4076)$ (Table 2). Post hoc analyses showed that N2-P2 amplitudes for the SL $(33.0 \pm 8.7 \mu \mathrm{V})$ and CL $(38.1 \pm 11.5 \mu \mathrm{V})$ were significantly larger than that for the $\mathrm{ES}(22.6 \pm 4.3 \mu \mathrm{V}: \mathrm{P}=$ 0.0025 for SL; $\mathrm{P}=0.0001$ for $\mathrm{CL}$ ). There was no significant difference in N2-P2 amplitudes between the SL and the CL.

The Friedman test indicated that the VAS scores differed significantly among the four stimulation conditions $(\mathrm{P}<0.0001)$ (Table 2). Post hoc analyses indicated that the VAS score for the SL ( $6.4 \pm 4.7$ points) was significantly smaller than that for the CL $(17.9 \pm 10.6$ points: $\mathrm{P}<$ $0.0001)$ and larger than that for the ES $(3.8 \pm 3.7$ points: $\mathrm{P}=0.0348)$. The VAS score for the $\mathrm{CL}$ was significantly larger than those for the ES $(\mathrm{P}<0.0001)$ and IES $(8.4 \pm 6.6$ points: $\mathrm{P}<$ $0.0001)$. In addition, the VAS score for the IES was significantly larger than that for the ES ( $\mathrm{P}=$ 0.0002). There was no significant difference in the VAS scores between the SL and the IES.

There were no correlations between the VAS scores and N2 or P2 latencies, or between the VAS scores and N2-P2 amplitudes, at any stimulation condition.

330 


\section{Discussion}

332 Here, we examined whether lance stimulation could selectively activate the free nerve endings of

333

334

335

336

337

338

339

340

341

342

343

344

345

346

347

348

349

350

351

352

353

354

355

356

357

358

359

360

361

362

363

364

365

366

367

368

369

370

A $\delta$ fibers. Specifically, we examined the effect of the click sound produced by the lance device on the ERPs evoked by skin puncture in Experiment 1, and compared the ERPs elicited by a custom-made shallow lance stimulation with those elicited by commonly clinically used lance stimulation, ES, and IES in Experiment 2. The present study revealed that the click sound shortened the latency of the ERP evoked by skin puncture and that the latencies of ERPs evoked by both lance stimulations (SL and CL) were shorter than those evoked by IES but similar to those evoked by ES.

\section{Effect of the click sound on the ERPs evoked by skin puncture}

When a click sound was present (click-only and click+SL), the N2 latencies of ERPs in response to click-only and click+SL and the P2 latencies of ERPs in response to the click-only condition were within the range reported in previous studies investigating ERPs of auditory stimuli (Wolpaw \& Penry, 1975; Knight et al., 1980; Carrillo-de-la-Peña \& Cadaveira, 2000; Atcherson et al., 2006; Gondan \& Röder, 2006; Gondan, Vorberg \& Greenlee, 2007; Touge et al., 2008; Sakamoto, Nakata \& Kakigi, 2009; Sperdin et al., 2009). N100, which can be observed in response to simple short auditory stimuli, reflects multiple mechanisms and is thought to originate from a wide range of areas (Näätänen \& Picton, 1987; Martin, Tremblay \& Korczak, 2008; Sakamoto, Nakata \& Kakigi, 2009), such as Heschl's gyrus, the temporal lobe (Okamoto et al., 2007; Altmann et al., 2008), auditory association areas (Knight et al., 1980), and frontal areas (Wolpaw \& Penry, 1975; Atcherson et al., 2006). P200, which can be observed following N100, has not been investigated to the same extent as N100, but is also thought to originate from a variety of areas in the cortex (Wolpaw \& Penry, 1975; Näätänen \& Picton, 1987; Martin, Tremblay \& Korczak, 2008). Although the exact mechanisms behind the ERPs evoked by auditory stimuli have not been fully determined, the click sound produced by the lance device appears to generate an auditory evoked potential.

\section{Possibility of multimodal ERPs evoked by lance stimulation}

In the present study, the $\mathrm{N} 2$ latencies of ERPs generated by click+SL were similar to those of click-only, and the P2 latencies of ERPs in response to click+SL were similar to those of SL (without the click sound), indicating that lance stimulation elicits an ERP composed of multimodal stimuli, namely the click sound and skin puncture. In previous studies on multimodal brain responses, multimodal ERPs were reported to be not simply a sum of the ERPs of each unimodal stimulus (Gondan \& Röder, 2006; Gondan, Vorberg \& Greenlee, 2007; Touge et al., 2008; Sperdin et al., 2009; Brett-Green et al., 2010; Dionne, Legon \& Staines, 2013). Specifically, in these studies, ERPs generated by unimodal stimuli (i.e., auditory (A) or visual (V) alone) and ERPs of bimodal stimuli (i.e., AV) were recorded, and the ERPs of bimodal stimuli were compared with the sum of the two unimodal ERPs (i.e., A + V) (Foxe et al., 2000; Gondan \& Röder, 2006; Gondan, Vorberg \& Greenlee, 2007; Touge et al., 2008; Brett-Green et

Peer) reviewing PDF | (2021:02:58128:2:0:NEW 11 Sep 2021) 
371 al., 2010). Their results revealed that the ERPs of bimodal stimuli did not match the sum of the 372 two unimodal ERPs (i.e., AV $\neq(\mathrm{A}+\mathrm{V})$ ) (Foxe et al., 2000; Gondan \& Röder, 2006; Gondan, 373 Vorberg \& Greenlee, 2007; Touge et al., 2008; Brett-Green et al., 2010), meaning that the ERPs 374 of bimodal stimuli reflect, in addition to the processing associated with the unimodal stimuli, 375 brain activity related to the interaction of two different unimodal stimuli (Gondan \& Röder, 376 2006; Gondan, Vorberg \& Greenlee, 2007).

377 Similarly, previous studies on brain responses to multimodal auditory-somatosensory 378 stimuli have shown that the N2 of ERPs of multimodal auditory-somatosensory stimuli were 379 similar to those of unimodal auditory stimuli (click sound), while the P2 of ERPs of multimodal

380

381

382

383

384

385

386

387

388

389

390

391

392

393

394

395

396

397

398

399

400

401

402

403

404

405

406

407

408

409

410

auditory-somatosensory stimuli were similar to those of unimodal somatosensory stimuli (electrical stimulation) (Touge et al., 2008; Brett-Green et al., 2010). Our finding is in agreement with this result, suggesting the interaction of auditory and somatosensory stimuli (Gobbelé et al., 2003). As the posterior parietal (Gobbelé et al., 2003), auditory (Foxe et al., 2000, 2002; Gobbelé et al., 2003), and secondary somatosensory (SII) cortices (Lam et al., 1999; Lütkenhöner et al., 2002; Gobbelé et al., 2003) are reported to be involved in auditory-somatosensory information processing, these brain areas may have been activated during the lance stimulation. It can be speculated that lance stimulation (with the click sound) elicits a multimodal ERP of auditory and puncture stimuli, which is different from the sum of two unimodal ERPs and is considered to possibly indicate an interaction of these two stimuli.

\section{Activation of $A \beta$ fibers by SL}

The latencies of the ERPs of the ES and IES in this study were within the range reported in previous studies (Inui et al., 2002; Mouraux, Iannetti \& Plaghki, 2010; Otsuru et al., 2010; Kodaira, Inui \& Kakigi, 2014; Mouraux, Marot \& Legrain, 2014; Omori et al., 2017; Kirimoto et al., 2018). The IES produces an electrical current in the epidermis and selectively activates free nerve endings of A $\delta$ fibers when low stimulation current intensities are applied (Mouraux, Iannetti \& Plaghki, 2010). In contrast, the electrical current produced by the ES reaches the deeper dermis where receptors of $A \beta$ fibers, which have a lower threshold than $A \delta$ fibers, are located (Mouraux, Iannetti \& Plaghki, 2010). These receptors respond to vibration, indentation, and forces applied to the skin (Johnson, 2001; Macefield, 2005). Therefore, the IES and ES used in the present study can be considered to have activated the free nerve endings of A $\delta$ fibers in the epidermis and the receptors of $\mathrm{A} \beta$ fibers in the deeper dermis, respectively.

On the other hand, the latencies of the ERPs of the SL in the present study were not within a range reflecting the activation of A $\delta$ fibers, even though the blade of the lance device was inserted to a depth of $0.1 \mathrm{~mm}$ into the epidermis where the free nerve endings of A $\delta$ fibers are located, and the effect of click sound was removed. It is likely that the SL generated a penetration force when the blade was inserted into the skin, activating the $A \beta$ fibers. The penetration force has been shown to be the largest force in the process of insertion (Meyer et al., 2014; Leonardi, Viganò \& Nicolucci, 2019). For example, a venipuncture needle [27 and 30 gauge $(\mathrm{G}) ; 8 \mathrm{~mm}$ length] produces a penetration force of $0.23-0.34 \mathrm{~N}$ (Egekvist, Bjerring \& 
411 Arendt-Nielsen, 1999), a hypodermic needle pen (31-34 G; 3.5-8.0 mm length) used for insulin

412 injection produces a penetration force of $0.36-0.73 \mathrm{~N}$ (Leonardi, Viganò \& Nicolucci, 2019), and 413 a needle used for sclerotomy ( $23 \mathrm{G} ; 2.30-3.96 \mathrm{~mm}$ length) produces a penetration force of $0.48-$ $4142.16 \mathrm{~N}$ (Meyer et al., 2014). Although the blade of the SL has a different shape (about $0.1 \mathrm{~mm}$ in 415 length and about $0.25 \mathrm{~mm}$ wide) from those needles listed above, we speculate that it generates a 416 penetration force. Indeed, the N2 and P2 latencies of the lance ERPs in this study were similar to 417 those of ERPs evoked by lance stimuli in previous studies [N2: $130 \pm 40 \mathrm{~ms}, \mathrm{P} 2: 258 \pm 61 \mathrm{~ms}$

418 (Fabrizi et al., 2013); N2: $102 \mathrm{~ms}$, P2: $249.5 \mathrm{~ms}$ (Fabrizi et al., 2016)], and they were also within 419 the range reported in previous studies examining ERPs generated by the stimulation of $\mathrm{A} \beta$ fibers 420 (Inui et al., 2002; Mouraux, Iannetti \& Plaghki, 2010; Otsuru et al., 2010). As reported in an 421 early study comparing mechanical and transcutaneous ES, in short-latency somatosensory 422 evoked potential components, such as N20, mechanical stimulation with a needle (pain) does not 423 differ significantly from mechanical stimulation with a plastic ball (tactile) and transcutaneous 424 ES (Kakigi \& Shibasaki, 1984), supporting our argument. Meanwhile, one may argue that the 425 increased N2-P2 amplitude in the CL and SL as compared to the ES can reflect the activation of 426 A $\delta$ fibers. However, given the latencies of $\mathrm{N} 2$ and $\mathrm{P} 2$, it is reasonable to assume that the CL and 427 SL activated more cutaneous mechanoreceptors (e.g., vibration receptors in the deeper dermis 428 layer) than the ES. Therefore, it is most likely that the SL activated the A $\beta$ fibers by the 429 penetration force associated with blade insertion, even though the blade was inserted only into 430 the epidermis.

431

432

433

\section{Mismatch between ERPs and Pain Perception}

The pain score on the VAS for the IES was not different from that for the SL, but was smaller than that for the CL. Some previous studies have reported that ERP amplitude is associated with the intensity of pain perception (Beydoun et al., 1993; García-Larrea et al., 1997; Ohara et al., 2004; Iannetti et al., 2005). However, nociceptive brain responses have been observed without pain perception in other studies in which ERP was evoked by the activation of A $\delta$ fibers using IES that did not reach the pain threshold (Hagiwara et al., 2018), by laser stimulation under anesthesia in monkeys (Baumgärtner et al., 2006), and by unperceived painful laser stimulation in humans (Lee, Mouraux \& Iannetti, 2009). Additionally, ERPs evoked by electric and laser stimulations are known to be modulated by stimuli expectations (Hird et al., 2018). Indeed, in the present study, we found no correlation between the VAS score and ERP latency or between the VAS score and ERP amplitude under any stimulation conditions. Thus, it seems to be difficult to evaluate pain using ERP amplitude.

Moreover, it has been reported that painful stimuli do not induce nociceptive brain responses when A $\beta$ fibers are activated simultaneously (Torquati et al., 2003; Rustamov et al., 2016). In this case, the ES current reaches the dermis where A $\beta$ fiber receptors are found with lower activation thresholds than those of the free endings of $A \delta$ fibers. Hence, even if the subjects felt pain with the SL, the $A \beta$ fiber receptors could have been activated initially, which may have masked the activation of $A \delta$ fibers. 
451

452

453

454

455

456

457

458

459

460

461

462

463

464

465

466

467

468

469

470

471

472

473

474

475

476

477

478

479

480

481

482

483

484

485

486

487

488

489

490

491

\section{Conclusions}

The click sound produced by the lance device influences the ERPs evoked by skin puncture.

Furthermore, the latency of the ERP of lance stimulation was shorter than that of IES and similar to that of $E S$, which suggests that $A \beta$ fibers are activated by lance stimulation. Lance ERPs, therefore, may reflect the activation of $A \beta$ fibers rather than $A \delta$ fibers. A pain index that correctly and reliably reflects nociceptive processing must be developed to improve pain assessment and management in neonates.

\section{Acknowledgements}

We would like to thank all the participants for their time and effort.

\section{References}

Altmann CF, Nakata H, Noguchi Y, Inui K, Hoshiyama M, Kaneoke Y, Kakigi R. 2008.

Temporal dynamics of adaptation to natural sounds in the human auditory cortex. Cerebral Cortex 18:1350-1360. DOI: 10.1093/cercor/bhm 166 .

Anderson P, Doyle LW. 2003. Neurobehavioral Outcomes of School-age Children Born Extremely Low Birth Weight or Very Preterm in the 1990s. Journal of the American Medical Association 289:3264-3272. DOI: 10.1001/jama.289.24.3264.

Atcherson SR, Gould HJ, Pousson MA, Prout TM. 2006. Long-term stability of N1 sources using low-resolution electromagnetic tomography. Brain Topography 19:11-20. DOI: 10.1007/s10548-006-0008-8.

Baumgärtner U, Greffrath W, Treede RD. 2012. Contact heat and cold, mechanical, electrical and chemical stimuli to elicit small fiber-evoked potentials: Merits and limitations for basic science and clinical use. Neurophysiologie Clinique 42:267-280. DOI: 10.1016/j.neucli.2012.06.002.

Baumgärtner U, Tiede W, Treede RD, Craig AD. 2006. Laser-evoked potentials are graded and somatotopically organized anteroposteriorly in the operculoinsular cortex of anesthetized monkeys. Journal of Neurophysiology 96:2802-2808. DOI: 10.1152/jn.00512.2006.

Beydoun A, Morrow TJ, Shen JF, Casey KL. 1993. Variability of laser-evoked potentials: attention, arousal and lateralized differences. Electroencephalography and Clinical Neurophysiology/ Evoked Potentials Section 88:173-181. DOI: 10.1016/01685597(93)90002-7.

Bromm B, Jahnke MT, Treede RD. 1984. Responses of human cutaneous afferents to CO2 laser stimuli causing pain. Experimental Brain Research 55:158-166. DOI: 10.1007/BF00240510.

Brett-Green BA, Miller LJ, Schoen SA, Nielsen DM. 2010. An exploratory event-related potential study of multisensory integration in sensory over-responsive children. Brain Research 1321:67-77. DOI: 10.1016/j.brainres.2010.01.043. 
492 Brummelte S, Grunau RE, Chau V, Poskitt KJ, Brant R, Vinall J, Gover A, Synnes AR, Miller

493

494

495

496

497

498

499

500

501

502

503

504

505

506

507

508

509

510

511

512

513

514

515

516

517

518

519

520

521

522

523

524

525

526

527

528

529

530

531

532

533

534

535

536
SP. 2012. Procedural pain and brain development in premature newborns. Annals of Neurology 71:385-396. DOI: 10.1002/ana.22267.

Campbell-Yeo M. 2019. Combining facilitated tucking and non-nutritive sucking appears to promote greater regulation for preterm neonates following heel lance, but does not provide effective pain relief. Evidence Based Nursing 22:19-19. DOI: 10.1136/ebnurs-2018102984.

Carrillo-de-la-Peña M., Cadaveira F. 2000. The effect of motivational instructions on P300 amplitude. Neurophysiologie Clinique/Clinical Neurophysiology 30:232-239. DOI: 10.1016/s0987-7053(00)00220-3.

Cruz MD, Fernandes AM, Oliveira CR. 2016. Epidemiology of painful procedures performed in neonates: A systematic review of observational studies. European Journal of Pain 20:489498. DOI: 10.1002/ejp.757.

Davari S, Borimnejad L, Khosravi S, Haghani H. 2019. The effect of the facilitated tucking position on pain intensity during heel stick blood sampling in premature infants: a surprising result. The Journal of Maternal-Fetal \& Neonatal Medicine 32:3427-3430. DOI: 10.1080/14767058.2018.1465550.

Dionne JK, Legon W, Staines WR. 2013. Crossmodal influences on early somatosensory processing: Interaction of vision, touch, and task-relevance. Experimental Brain Research 226:503-512. DOI: 10.1007/s00221-013-3462-z.

Egekvist, Bjerring, Arendt-Nielsen. 1999. Pain and mechanical injury of human skin following needle insertions. European Journal of Pain 3:41-49. DOI: 10.1053/eujp.1998.0099.

Fabrizi L, Verriotis M, Williams G, Lee A, Meek J, Olhede S, Fitzgerald M. 2016. Encoding of mechanical nociception differs in the adult and infant brain. Scientific Reports 6:2-10. DOI: 10.1038/srep28642.

Fabrizi L, Williams G, Lee A, Meek J, Slater R, Olhede S, Fitzgerald M. 2013. Cortical activity evoked by an acute painful tissue-damaging stimulus in healthy adult volunteers. Journal of Neurophysiology 109:2393-2403. DOI: 10.1152/jn.00990.2012.

Foxe JJ, Morocz IA, Murray MM, Higgins BA, Javitt DC, Schroeder CE. 2000. Multisensory auditory-somatosensory interactions in early cortical processing revealed by high-density electrical mapping. Cognitive Brain Research 10:77-83. DOI: 10.1016/S09266410(00)00024-0.

Gao H, Li M, Gao H, Xu G, Li F, Zhou J, Zou Y, Jiang H. 2018. Effect of non-nutritive sucking and sucrose alone and in combination for repeated procedural pain in preterm infants: A randomized controlled trial. International Journal of Nursing Studies 83:25-33. DOI: 10.1016/j.ijnurstu.2018.04.006.

García-Larrea L, Peyron R, Laurent B, Mauguière F. 1997. Association and dissociation between laser-evoked potentials and pain perception. Neuroreport 8:3785-93789. DOI: 10.1097/00001756-199712010-00026.

Gibbins S, Stevens BJ, Yamada J, Dionne K, Campbell-Yeo M, Lee G, Caddell K, Johnston C, Taddio A. 2014. Validation of the Premature Infant Pain Profile-Revised (PIPP-R). Early Human Development 90:189-193. DOI: 10.1016/j.earlhumdev.2014.01.005.

Gobbelé R, Schürmann M, Forss N, Juottonen K, Buchner H, Hari R. 2003. Activation of the human posterior parietal and temporoparietal cortices during audiotactile interaction. NeuroImage 20:503-511. DOI: 10.1016/S1053-8119(03)00312-4. 
537

538

539

540

541

542

543

544

545

546

547

548

549

550

551

552

553

554

555

556

557

558

559

560

561

562

563

564

565

566

567

568

569

570

571

572

573

574

575

576

577

578

579

580

581

Gondan M, Röder B. 2006. A new method for detecting interactions between the senses in eventrelated potentials. Brain Research 1073-1074:389-397. DOI:

10.1016/j.brainres.2005.12.050.

Gondan M, Vorberg D, Greenlee MW. 2007. Modality shift effects mimic multisensory interactions: An event-related potential study. Experimental Brain Research 182:199-214. DOI: $10.1007 / \mathrm{s} 00221-007-0982-4$.

Grunau RE, Whitfield MF, Fay TB. 2004. Psychosocial and academic characteristics of extremely low birth weight $(\leq 800 \mathrm{~g})$ adolescents who are free of major impairment compared with term-born control subjects. Pediatrics 114:e725-732. DOI: 10.1542/peds.2004-0932.

Grunau RE, Whitfield MF, Petrie-Thomas J, Synnes AR, Cepeda IL, Keidar A, Rogers M, MacKay M, Hubber-Richard P, Johannesen D. 2009. Neonatal pain, parenting stress and interaction, in relation to cognitive and motor development at 8 and 18 months in preterm infants. Pain 143:138-146. DOI: 10.1016/j.pain.2009.02.014.

Hagiwara K, Perchet C, Frot M, Bastuji H, Garcia-Larrea L. 2018. Insular-limbic dissociation to intra-epidermal electrical $A \delta$ activation: A comparative study with thermo-nociceptive laser stimulation. European Journal of Neuroscience 48:3186-3198. DOI: 10.1111/ejn.14146.

Hartley C, Goksan S, Poorun R, Brotherhood K, Mellado GS, Moultrie F, Rogers R, Adams E, Slater R. 2015. The relationship between nociceptive brain activity, spinal reflex withdrawal and behaviour in newborn infants. Scientific Reports 5:1-13. DOI: 10.1038/srep12519.

Hird EJ, Jones AKP, Talmi D, El-Deredy W. 2018. A comparison between the neural correlates of laser and electric pain stimulation and their modulation by expectation. Journal of Neuroscience Methods 293:117-127. DOI: 10.1016/j.jneumeth.2017.09.011.

Iannetti GD, Zambreanu L, Cruccu G, Tracey I. 2005. Operculoinsular cortex encodes pain intensity at the earliest stages of cortical processing as indicated by amplitude of laserevoked potentials in humans. Neuroscience 131:199-208. DOI: 10.1016/j.neuroscience.2004.10.035.

Inui K, Tran TD, Hoshiyama M, Kakigi R. 2002. Preferential stimulation of A $\delta$ fibers by intraepidermal needle electrode in humans. Pain 96:247-252. DOI: 10.1016/S03043959(01)00453-5.

Johnson KO. 2001. The roles and functions of cutaneous mechanoreceptors. Current Opinion in Neurobiology 11:455-461. DOI: 10.1016/S0959-4388(00)00234-8.

Kakigi R, Shibasaki H. 1984. Scalp topography of mechanically and electrically evoked somatosensory potentials in man. Electroencephalography and Clinical Neurophysiology/ Evoked Potentials Section 59:44-56. DOI: 10.1016/0168-5597(84)90019-4.

Kakigi R, Shibasaki H, Ikeda A. 1989. Pain-related somatosensory evoked potentials following CO2 laser stimulation in man. Electroencephalography and Clinical Neurophysiology/ Evoked Potentials Section 74:139-146. DOI: 10.1016/0168-5597(89)90019-1.

Kirimoto H, Tamaki H, Otsuru N, Yamashiro K, Onishi H, Nojima I, Oliviero A. 2018. Transcranial static magnetic field stimulation over the primary motor cortex induces plastic changes in cortical nociceptive processing. Frontiers in Human Neuroscience 12:1-10. DOI: $10.3389 /$ fnhum.2018.00063.

Knight RT, Hillyard SA, Woods DL, Neville HJ. 1980. The effects of frontal and temporalparietal lesions on the auditory evoked potential in man. Electroencephalography and clinical neurophysiology 50:112-24. DOI: 10.1016/0013-4694(80)90328-4. 
582 Kodaira M, Inui K, Kakigi R. 2014. Evaluation of nociceptive A $\delta$ - and C-fiber dysfunction with 583 lidocaine using intraepidermal electrical stimulation. Clinical Neurophysiology 125:1870584 1877. DOI: 10.1016/j.clinph.2014.01.009.

585

586

587

588

589

590

591

592

593

594

595

596

597

598

599

600

601

602

603

604

605

606

607

608

609

610

611

612

613

614

615

616

617

618

619

620

621

622

623

624

625

Lam K, Kakigi R, Kaneoke Y, Naka D, Maeda K, Suzuki H. 1999. Effects of visual and auditory stimulation on somatosensory evoked magnetic fields. Clinical Neurophysiology 110:295304. DOI: 10.1016/S0168-5597(98)00059-8.

Lax ID, Duerden EG, Lin SY, Mallar Chakravarty M, Donner EJ, Lerch JP, Taylor MJ. 2013. Neuroanatomical consequences of very preterm birth in middle childhood. Brain Structure and Function 218:575-585. DOI: 10.1007/s00429-012-0417-2.

Lee MC, Mouraux A, Iannetti GD. 2009. Characterizing the cortical activity through which pain emerges from nociception. Journal of Neuroscience 29:7909-7916. DOI: 10.1523/JNEUROSCI.0014-09.2009.

Lefaucheur JP, Ahdab R, Ayache SS, Lefaucheur-Ménard I, Rouie D, Tebbal D, Neves DO, Ciampi de Andrade D. 2012. Pain-related evoked potentials: A comparative study between electrical stimulation using a concentric planar electrode and laser stimulation using a $\mathrm{CO}_{2}$ laser. Neurophysiologie Clinique 42:199-206. DOI: 10.1016/j.neucli.2011.12.003.

Leonardi L, Viganò M, Nicolucci A. 2019. Penetration force and cannula sliding profiles of different pen needles: The PICASSO study. Medical Devices: Evidence and Research 12:311-317. DOI: 10.2147/MDER.S218983.

Loe IM, Lee ES, Luna B, Feldman HM. 2011. Behavior problems of 9-16 year old preterm children: Biological, sociodemographic, and intellectual contributions. Early Human Development 87:247-252. DOI: 10.1016/j.earlhumdev.2011.01.023.

Lütkenhöner B, Lammertmann C, Simões C, Hari R. 2002. Magnetoencephalographic correlates of audiotactile interaction. NeuroImage 15:509-522. DOI: 10.1006/nimg.2001.0991.

Macefield VG. 2005. Proceedings of the Symposium From Osseointegration to Osseoperception: The functional translation physiological characteristics of low-threshold mechanoreceptors in joints, muscle and skin in Clinical and Experimental Pharmacology and Physiology (2005) 32:135-144.

Martin BA, Tremblay KL, Korczak P. 2008. Speech evoked potentials: From the laboratory to the clinic. Ear and Hearing 29:285-313. DOI: 10.1097/AUD.0b013e3181662c0e.

Meyer CH, Kaymak H, Liu Z, Saxena S, Rodrigues EB. 2014. Geometry, penetration force, and cutting profile of different 23-gauge trocars systems for pars plana vitrectomy. Retina 34:2290-2299. DOI: 10.1097/IAE.0000000000000221.

Moultrie F, Slater R, Hartley C. 2017. Improving the treatment of infant pain. Current Opinion in Supportive and Palliative Care 11:112-117. DOI: 10.1097/SPC.0000000000000270.

Mouraux A, Iannetti GD, Plaghki L. 2010. Low intensity intra-epidermal electrical stimulation can activate A $\delta$-nociceptors selectively. Pain 150:199-207. DOI: 10.1016/j.pain.2010.04.026.

Mouraux A, Marot E, Legrain V. 2014. Short trains of intra-epidermal electrical stimulation to elicit reliable behavioral and electrophysiological responses to the selective activation of nociceptors in humans. Neuroscience Letters 561:69-73. DOI: 10.1016/j.neulet.2013.12.017.

Munger BL, Halata Z. 1983. The sensory innervation of primate facial skin. I. Hairy skin. Brain Research Reviews 5:45-80. DOI: 10.1016/0165-0173(83)90021-8. 
626

627

628

629

630

631

632

633

634

635

636

637

638

639

640

641

642

643

644

645

646

647

648

649

650

651

652

653

654

655

656

657

658

659

660

661

662

663

664

665

666

667

668

669

Näätänen R, Picton T. 1987. The N1 Wave of the Human Electric and Magnetic Response to Sound: A Review and an Analysis of the Component Structure. Psychophysiology 24:375425. DOI: 10.1111/j.1469-8986.1987.tb00311.x.

Nosarti C, Al-Asady MHS, Frangou S, Stewart AL, Rifkin L, Murray RM. 2002. Adolescents who were born very preterm have decreased brain volumes. Brain 125:1616-1623. DOI: 10.1093/brain/awf157.

Nosarti C, Giouroukou E, Healy E, Rifkin L, Walshe M, Reichenberg A, Chitnis X, Williams SCR, Murray RM. 2008. Grey and white matter distribution in very preterm adolescents mediates neurodevelopmental outcome. Brain 131:205-217. DOI: 10.1093/brain/awm282.

Novotny GE, Gommert-Novotny E. 1988. Intraepidermal nerves in human digital skin. Cell and Tissue Research 254:111-117. DOI: 10.1007/BF00220023.

Ohara S, Crone NE, Weiss N, Treede RD, Lenz FA. 2004. Amplitudes of laser evoked potential recorded from primary somatosensory, parasylvian and medial frontal cortex are graded with stimulus intensity. Pain 110:318-328. DOI: 10.1016/j.pain.2004.04.009.

Okamoto H, Stracke H, Wolters CH, Schmael F, Pantev C. 2007. Attention improves populationlevel frequency tuning in human auditory cortex. Journal of Neuroscience 27:10383-10390. DOI: 10.1523/JNEUROSCI.2963-07.2007.

Omori S, Isose S, Misawa S, Watanabe K, Sekiguchi Y, Shibuya K, Beppu M, Amino H, Kuwabara S. 2017. Pain-related evoked potentials after intraepidermal electrical stimulation to $\mathrm{A} \delta$ and $\mathrm{C}$ fibers in patients with neuropathic pain. Neuroscience Research 121:43-48. DOI: 10.1016/j.neures.2017.03.007.

Otsuru N, Inui K, Yamashiro K, Miyazaki T, Takeshima Y, Kakigi R. 2010. Assessing A $\delta$ fiber function with lidocaine using intraepidermal electrical stimulation. The Journal of Pain 11:621-627. DOI: 10.1016/j.jpain.2009.10.001.

Peng HF, Yin T, Yang L, Wang C, Chang YC, Jeng MJ, Liaw JJ. 2018. Non-nutritive sucking, oral breast milk, and facilitated tucking relieve preterm infant pain during heel-stick procedures: A prospective, randomized controlled trial. International Journal of Nursing Studies 77:162-170. DOI: 10.1016/j.ijnurstu.2017.10.001.

Perroteau A, Nanquette MC, Rousseau A, Renolleau S, Bérard L, Mitanchez D, Leblanc J. 2018. Efficacy of facilitated tucking combined with non-nutritive sucking on very preterm infants' pain during the heel-stick procedure: A randomized controlled trial. International Journal of Nursing Studies 86:29-35. DOI: 10.1016/j.ijnurstu.2018.06.007.

Picton TW, Alain C, Woods DL, John MS, Scherg M, Valdes-Sosa P, Bosch-Bayard J, Trujillo NJ. 1999. Intracerebral sources of human auditory-evoked potentials. Audiology \& neurootology 4:64-79. DOI: 10.1159/000013823.

Pillai Riddell R, Racine N, Gennis H, Turcotte K, Uman L, Horton R, Ahola Kohut S, Hillgrove Stuart J, Stevens B, Lisi D. 2015. Non-pharmacological management of infant and young child procedural pain. Cochrane Database of Systematic Reviews. DOI: 10.1002/14651858.CD006275.

Ranger M, Grunau RE. 2014. Early repetitive pain in preterm infants in relation to the developing brain. Pain Management 4:57-67. DOI: 10.2217/pmt.13.61.

Rustamov N, Tessier J, Provencher B, Lehmann A, Piché M. 2016. Inhibitory effects of heterotopic noxious counter-stimulation on perception and brain activity related to A $\beta$-fibre activation. European Journal of Neuroscience 44:1771-1778. DOI: 10.1111/ejn.13258.

Peer] reviewing PDF | (2021:02:58128:2:0:NEW 11 Sep 2021) 
670

671

672

673

674

675

676

677

678

679

680

681

682

683

684

685

686

687

688

689

690

691

692

693

694

695

696

697

698

699

700

701

702

703

704

705

706

707

708

709

710

711

712

713

714

715

Sakamoto K, Nakata H, Kakigi R. 2009. The effect of mastication on human cognitive processing: A study using event-related potentials. Clinical Neurophysiology 120:41-50. DOI: 10.1016/j.clinph.2008.10.001.

Schmidt LA, Miskovic V, Boyle M, Saigal S. 2010. Frontal electroencephalogram asymmetry, salivary cortisol, and internalizing behavior problems in young adults who were born at extremely low birth weight. Child Development 81:183-199. DOI: 10.1111/j.14678624.2009.01388.x.

Shiroshita Y, Kirimoto H, Nakagawa K, Uematsu H, Sobue I. 2020. Evoked Potential as a Pain Evaluation Index for Neonatal Procedural Pain. International Journal of Nursing \& Clinical Practices 7. DOI: 10.15344/2394-4978/2020/323.

Shiroshita Y, Kirimoto H, Ozawa M, Watanabe T, Uematsu H, Yunoki K, Sobue I. 2021. Can Event-Related Potentials Evoked by Heel Lance Assess Pain Processing in Neonates? A Systematic Review. Children 8:58. DOI: 10.3390/children8020058.

Slater R, Cornelissen L, Fabrizi L, Patten D, Yoxen J, Worley A, Boyd S, Meek J, Fitzgerald M. 2010a. Oral sucrose as an analgesic drug for procedural pain in newborn infants: A randomised controlled trial. The Lancet 376:1225-1232. DOI: 10.1016/S01406736(10)61303-7.

Slater R, Worley A, Fabrizi L, Roberts S, Meek J, Boyd S, Fitzgerald M. 2010b. Evoked potentials generated by noxious stimulation in the human infant brain. European Journal of Pain 14:321-326. DOI: 10.1016/j.ejpain.2009.05.005.

Sperdin HF, Cappe C, Foxe JJ, Murray MM. 2009. Interactions Impact Reaction Time Speed. Frontiers in Integrative Neuroscience 3:1-10. DOI: 10.3389/neuro.07.

Stevens B, Johnston C, Petryshen P, Taddio A. 1996. Premature Infant Pain Profile: development and initial validation. The Clinical Journal of Pain 12:13-22. DOI: 10.1097/00002508199603000-00004.

Stevens B, Yamada J, Ohlsson A, Haliburton S, Shorkey A. 2017. Sucrose for analgesia in newborn infants undergoing painful procedures. Cochrane Database of Systematice Reviews. DOI: 10.1002/14651858.CD001069.

Torquati K, Pizzella V, Della Penna S, Franciotti R, Babiloni C, Romani GL, Rossini PM. 2003. "Gating" effects of simultaneous peripheral electrical stimulations on human secondary somatosensory cortex: A whole-head MEG study. NeuroImage 20:1704-1713. DOI: 10.1016/S1053-8119(03)00439-7.

Touge T, Gonzalez D, Wu J, Deguchi K, Tsukaguchi M, Shimamura M, Ikeda K, Kuriyama S. 2008. The interaction between somatosensory and auditory cognitive processing assessed with event-related potentials. Journal of Clinical Neurophysiology 25:90-97. DOI: 10.1097/WNP.0b013e31816a8ffa.

Uematsu H, Sobue I. 2019. Effect of music (Brahms lullaby) and non-nutritive sucking on heel lance in preterm infants: A randomized controlled crossover trial. Paediatrics and Child Health 24:E33-E39. DOI: 10.1093/pch/pxy072.

Verriotis M, Fabrizi L, Lee A, Cooper RJ, Fitzgerald M, Meek J. 2016. Mapping cortical responses to somatosensory stimuli in human infants with simultaneous near-infrared spectroscopy and event-related potential recording. eNeuro 3:663-673. DOI: 10.1523/ENEURO.0026-16.2016.

Vinall J, Miller SP, Bjornson BH, Fitzpatrick KPV, Poskitt KJ, Brant R, Synnes AR, Cepeda IL, Grunau RE. 2014. Invasive procedures in preterm children: Brain and cognitive development at school age. Pediatrics 133:412-421. DOI: 10.1542/peds.2013-1863.

Peer] reviewing PDF | (2021:02:58128:2:0:NEW 11 Sep 2021) 
716 Walker SM. 2019. Long-term effects of neonatal pain. Seminars in Fetal and Neonatal Medicine 717 24:101005. DOI: 10.1016/j.siny.2019.04.005.

718 Walker SM, Melbourne A, O’Reilly H, Beckmann J, Eaton-Rosen Z, Ourselin S, Marlow N.

719 2018. Somatosensory function and pain in extremely preterm young adults from the UK

720 EPICure cohort: sex-dependent differences and impact of neonatal surgery. British Journal 721 of Anaesthesia 121:623-635. DOI: 10.1016/j.bja.2018.03.035.

722 Wolpaw JR, Penry JK. 1975. A temporal component of the auditory evoked response.

723

724 Electroencephalography and clinical neurophysiology 39:609-20. DOI: 10.1016/0013-

725 4694(75)90073-5. 


\section{Table 1 (on next page)}

ERPs latencies and amplitudes for three stimulation conditions. $(n=8)$

ERP: event-related potential, click-only: click sound produced by a lance device, click+SL: shallow lance stimulation with click sound, $\mathrm{WN}+\mathrm{SL}$ : shallow lance stimulation with white noise. 
2 Table1. ERPs latencies and amplitudes for three stimulation conditions. $(n=8)$

\begin{tabular}{ccccc}
\hline & \multicolumn{2}{c}{ Latency $(\mathrm{ms})$} & \multicolumn{2}{c}{ Amplitude $(\mu \mathrm{V})$} \\
& $\mathrm{N} 2$ & $\mathrm{P} 2$ & $\mathrm{~N} 2$ & $\mathrm{P} 2$ \\
\hline click-only & $122 \pm 2.9$ & $191 \pm 11.3$ & $-10.3 \pm 5.7$ & $14.8 \pm 5.0$ \\
click+SL & $121 \pm 6.5$ & $249 \pm 18.6$ & $-14.0 \pm 7.1$ & $21.4 \pm 4.9$ \\
WN+SL & $154 \pm 7.1$ & $253 \pm 11.2$ & $-6.8 \pm 5.2$ & $24.7 \pm 4.5$
\end{tabular}

3 ERP: event-related potential, click-only: click sound produced by a lance device, click + SL:

4 shallow lance stimulation with click sound, WN+SL: shallow lance stimulation with white noise. 5 


\section{Table 2 (on next page)}

ERPs latencies, amplitudes and VAS scores for four stimulation conditions. $(n=18)$

ERP: event-related potential, VAS: visual analogue scale, SL: shallow lance stimulation with white noise, $\mathrm{CL}$ : clinical lance stimulation with white noise, ES: transcutaneous electrical stimulation with white noise, IES: intraepidermal electrical stimulation with white noise. 
1 Table2. ERPs latencies, amplitudes and VAS scores for four stimulation conditions. ( $\mathrm{n}=18)$

\begin{tabular}{|c|c|c|c|c|}
\hline & \multicolumn{2}{|c|}{ Latency (ms) } & \multirow{2}{*}{$\begin{array}{c}\text { Amplitude }(\mu \mathrm{V}) \\
\text { N2-P2 }\end{array}$} & \multirow[t]{2}{*}{ VAS (points) } \\
\hline & $\mathrm{N} 2$ & $\mathrm{P} 2$ & & \\
\hline SL & $146 \pm 8.3$ & $250 \pm 18.2$ & $33.0 \pm 8.7$ & $6.4 \pm 4.7$ \\
\hline $\mathrm{CL}$ & $149 \pm 9.9$ & $251 \pm 14.1$ & $38.1 \pm 11.5$ & $17.9 \pm 10.6$ \\
\hline $\mathrm{ES}$ & $148 \pm 13.1$ & $237 \pm 26.3$ & $22.6 \pm 4.3$ & $3.8 \pm 3.7$ \\
\hline IES & $197 \pm 21.2$ & $294 \pm 30.0$ & $28.4 \pm 9.9$ & $8.4 \pm 6.6$ \\
\hline
\end{tabular}

2 ERP: event-related potential, VAS: visual analogue scale, SL: shallow lance stimulation with 3 white noise, CL: clinical lance stimulation with white noise, ES: transcutaneous electrical 4 stimulation with white noise, IES: intraepidermal electrical stimulation with white noise. 
Figure 1

Schema of the stand used for shallow lance stimulation (A) and insertion of a blade into the skin layers $(B)$.

The lancet device was fixed using a fixing stand for shallow lance stimulation. A space for a metal plate $(0.8 \mathrm{~mm}$ ) and a small gap (about $0.1 \mathrm{~mm}$ ) was made between the device and the skin surface. A blade was inserted into the epidermis. Free endings of $A \delta$ fibers are present in the epidermis, and A $\beta$ fiber receptors are present in the dermis (Munger \& Halata, 1983; Novotny \& Gommert-Novotny, 1988; Inui et al., 2002).

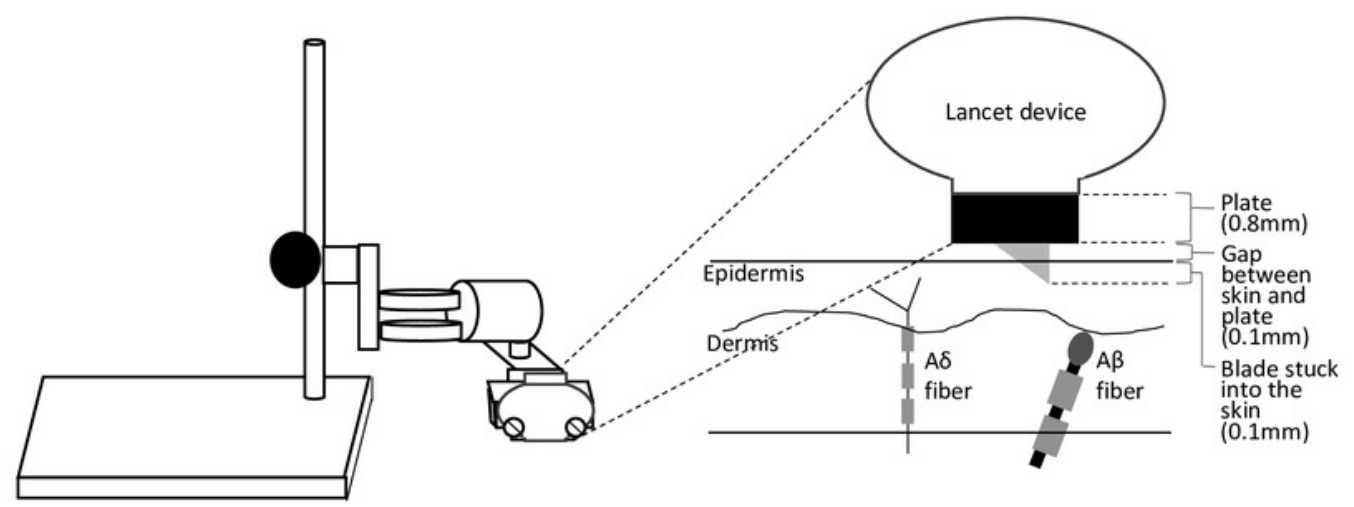


Figure 2

Grand averaged ERPs recorded from $\mathrm{Cz}$ evoked by three stimulation condition (clickonly, click+SL, and $W N+S L)(n=8)$.

click-only: click sound produced by a lance device; click+SL: shallow lance stimulation with click sound; WN+SL: shallow lance stimulation with white noise. Note the difference in ERP latency between the three types of stimulation. The shadow indicates the $95 \%$ confidence interval. 


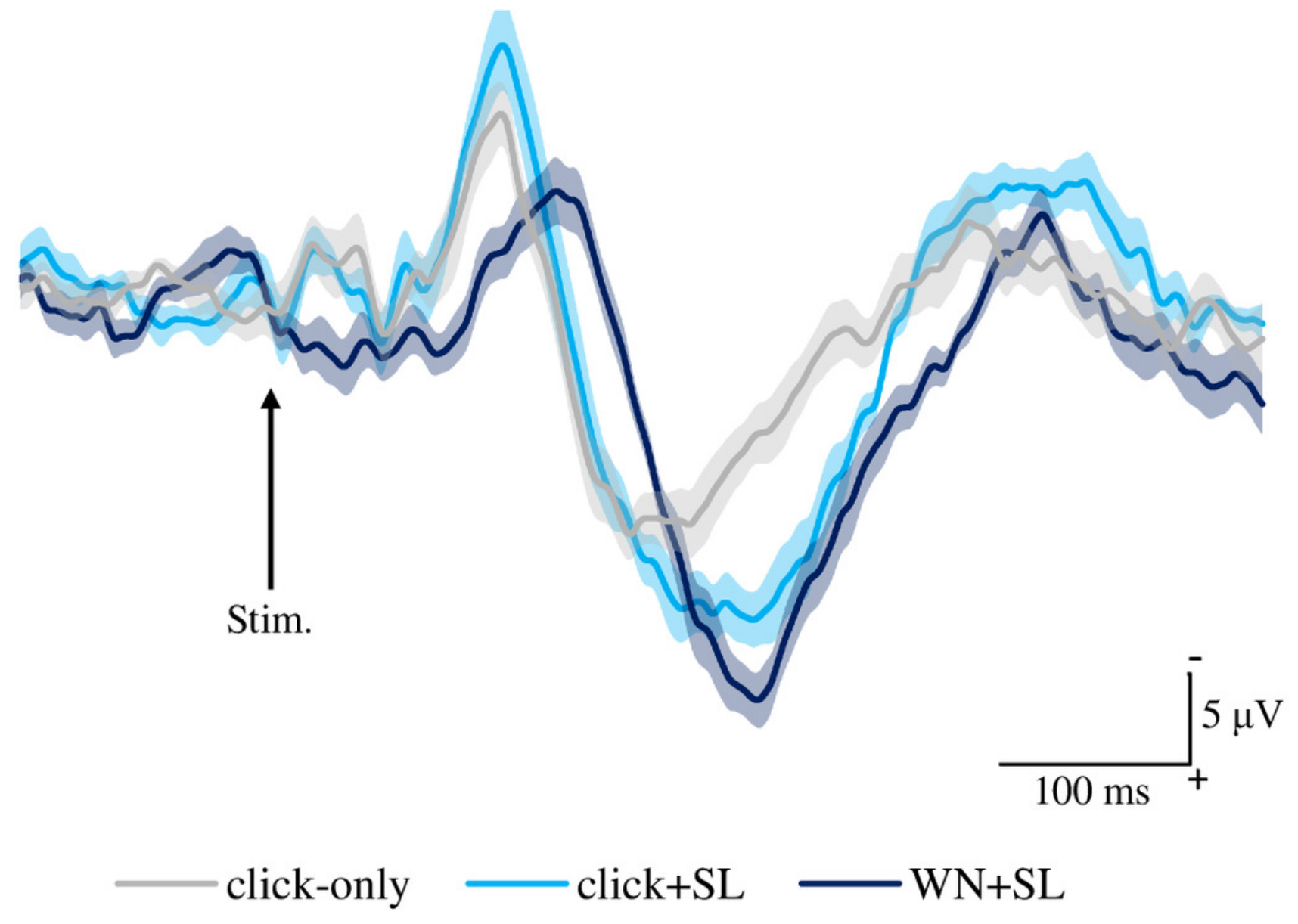


Figure 3

N2 (A) and P2 latencies (B) for three stimulation condition (click-only, click+SL, and $W N+S L)$.

Black and gray circles indicate the mean and the individual data, respectively. click-only: click sound produced by a lance device; click+SL: shallow lance stimulation with click sound; $\mathrm{WN}+\mathrm{SL}$ : shallow lance stimulation with white noise. Asterisks indicate significant post hoc differences.

(A)

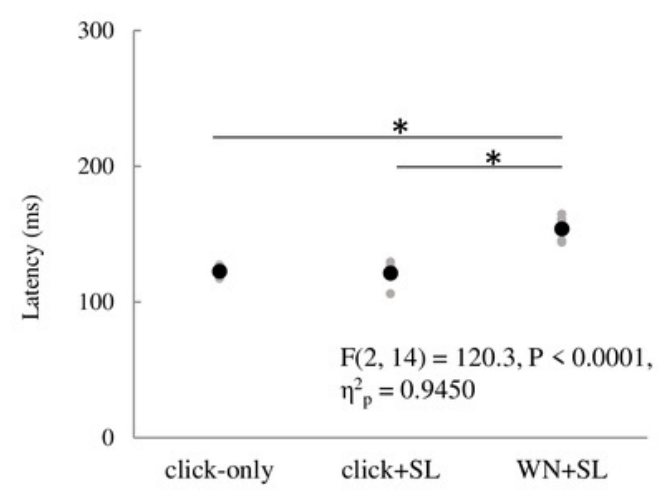

(B)

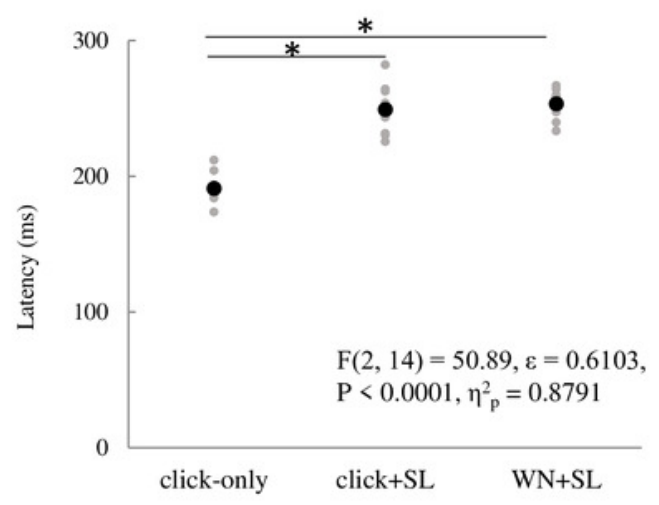




\section{Figure 4}

Grand averaged ERPs recorded from Cz evoked by four stimulation condition (SL, CL, $E S$, and IES) $(n=18)$.

SL: shallow lance stimulation with white noise; CL: clinical lance stimulation with white noise; ES: transcutaneous electrical stimulation with white noise; IES: intraepidermal electrical stimulation with white noise. Note the difference in ERP latency between the four types of stimulation. The shadow indicates the $95 \%$ confidence interval. 


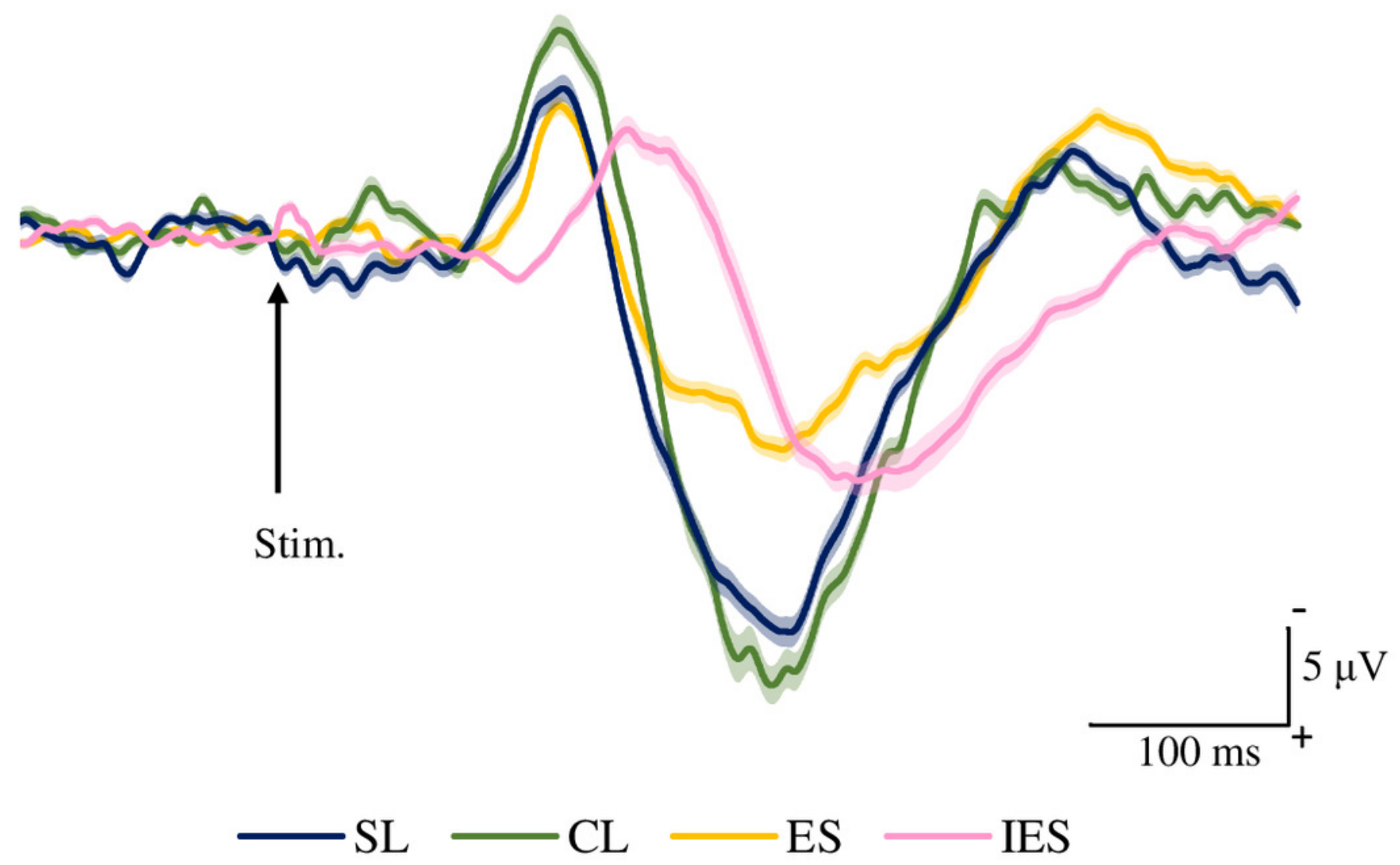


Figure 5

N2 (A) and P2 latencies (B) for four stimulation condition (SL, CL, ES, and IES).

Black and gray circles indicate the mean and the individual data, respectively. SL: shallow lance stimulation with white noise; $\mathrm{CL}$ : clinical lance stimulation with white noise; ES: transcutaneous electrical stimulation with white noise; IES: intraepidermal electrical stimulation with white noise. Asterisks indicate significant post hoc differences.

(A)

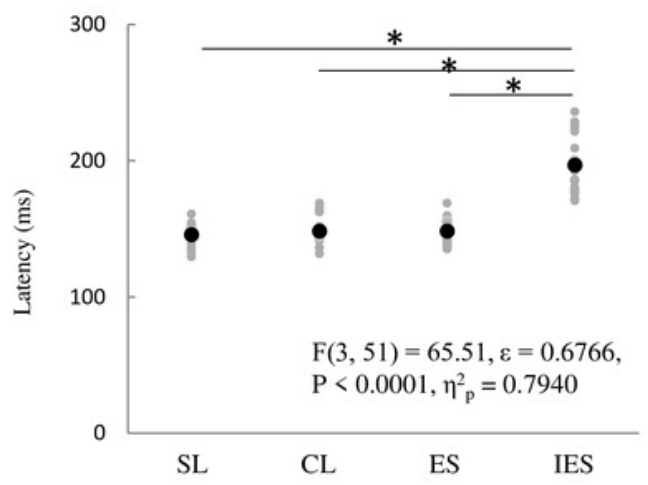

(B)

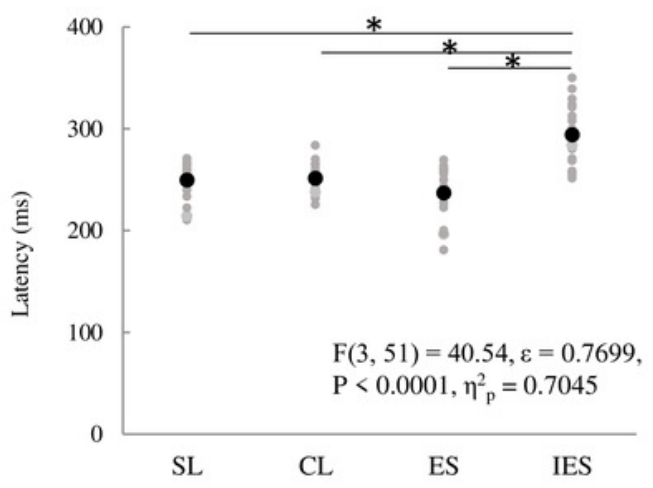

